\title{
GESTAÇÃO NA ADOLESCÊNCIA COM ENFOQUE NO CASAL: MOVIMENTO EXISTENCIAL ${ }^{a}$
}

\author{
Gestation in the Adolescence with focus on the couple: existential movement \\ Embarazo en la Adolescencia con enfoque en el casal: movimiento existencial
}

Inez Silva de Almeida ${ }^{1}$

Ivis Emília de Oliveira Souza²

\section{RESUMO}

A temática da gestação na adolescência, enfocada como patologia e risco sociais, tem sido visualizada a partir dos conceitos prévios da ciência e dos fatos sustentados em uma questão de gênero. Assim, a perspectiva do casal adolescente ainda se encontra obscura. Este estudo teve como objetivo analisar o movimento existencial do casal adolescente que vivencia uma gravidez. É um estudo qualitativo que utilizou a abordagem fenomenológica à luz dos conceitos de Martin Heidegger. A realização das entrevistas ocorreu de março a outubro de 2008. 0 cenário foi a Casa de Parto David Capistrano Filho, e os sujeitos foram nove casais adolescentes. Estudar o casal adolescente, em seu vivido da gestação, ou seja, no cotidiano de ser-casal, que é pai/mãe, permitiu construir outras possibilidades de cuidado sustentadas na instância ontológica, velada no cotidiano assistencial que é operacionalizado pelo protocolo de risco gestacional.

Palavras-chave: Gravidez na Adolescência. Adolescente. Assistência Perinatal.

\begin{abstract}
The thematic of the gestation in the adolescence, focused as social pathology and risk, have been visualized from the previous concepts of the science and the facts supported in a gender question. Thus, the adolescent couple' s perspective still is obscure. This qualitative study had as objective to analyze the existential movement of the adolescent couple that experiences a pregnancy. It is a study that used a phenomenological approach with the concepts of Martin Heidegger. The interviews realization occurred from March to October of 2008. The scenario was the House of Birth David Capistrano Filho and the subjects were 09 adolescent couple. To study the adolescent-couple, in its experience of be pregnant, give birth and nourish, in other words, in the daily of the be-couple, that is father/mother allowed to construct others possibilities of care supported in the ontological instance, veiled in the assistance daily that is operated by the protocol of gestational risk.
\end{abstract}

Keywords: Pregnancy in the Adolescence. Adolescent. Perinatal assistance.

\section{Resumen}

La temática del embarazo en la adolescencia, enfocada como patología y riesgo sociales, tienen sido visualizadas a partir de los conceptos previos de la ciencia y de los hechos sustentados en una cuestión de género. Así, la perspectiva del casal adolescente aún se encuentra obscura. Este estudio tuvo como objetivo analizar el movimiento existencial del casal adolescente que vivencia un embarazo. Es un estudio cualitativo que utiliza el abordaje fenomenológico a la luz de los conceptos de Martin Heidegger. La realización de las entrevistas ocurrió de marzo a octubre de 2008. El escenario fue a la Casa de Parto David Capistrano Filho y los sujetos fueron 09 parejas adolescentes. Estudiar el casal-adolescente, en el día a día del embarazo, o sea, en el cotidiano de ser-casal, que es padre/madre, permitió construir otras posibilidades de cuidado sustentadas en la instancia ontológica, velada en el cotidiano asistencial que es operado por el protocolo de riesgo en el embarazo.

Palabras-clave: Embarazo en Adolescencia, Adolescente, Asistencia Perinatal.

\footnotetext{
'Enfermeira, Doutora Enfermagem, Líder de Equipe do Ambulatório do NESA/ HUPE/UERJ. Professora Assistente do Departamento de Fundamentos de Enfermagem da Faculdade de Enfermagem da UERJ. Rio de Janeiro-RJ. Brasil.email:inezdealmeida@ig.com.br, ${ }^{2}$ Enfermeira, Doutora em Enfermagem, Professora Titular do Departamento de Enfermagem Materno-Infantil da Escola de Enfermagem Anna Nery, da UFRJ. Rio de Janeiro- RJ. Brasil. email:ivis@superig.com.br.
} 


\section{INTRODUÇÃO}

A temática da gravidez na adolescência, amplamente divulgada pela mídia e discutida por profissionais das várias áreas do conhecimento, tem sido problematizada a partir das concepções sócio-histórico-culturais construídas através dos tempos e vem ganhando destaque na área social ou científica, não por ser um fato novo, mas por representar um desafio ao setor de saúde. Apesar do empreendimento governamental, transformou-se em um problema de saúde pública, haja vista que, embora os índices de gestação na adolescência tenham se mantido relativamente estáveis na faixa etária de 15-19 anos, na faixa etária de 10-14 anos vêm-se apresentando em níveis crescentes e têm sido objeto de estudos. ${ }^{1}$

Esses índices servem tanto para questionar o aspecto vigente que rotula a gravidez em adolescentes como problema que fortalece o preconceito e a discriminação como para mostrar a necessidade de não se desviar o foco de atenção da saúde reprodutiva na adolescência pelo prisma do casal.

0 aumento expressivo de adolescentes grávidas tem sido popularizado, favorecendo sua visibilidade social, ainda inserido em um discurso vitimizador que rotula o fenômeno como instaurador de desordens e implicações múltiplas nas trajetórias dos jovens, sendo visto como responsável por maximizar transtornos, como o abandono escolar, a redução do padrão de vida, os conflitos familiares e o risco à saúde. ${ }^{2}$

Pela concepção vigente, o risco da gravidez relacionase à saúde da gestante adolescente e do concepto, os quais definem implicações biológicas e sociais, incluindo também a dimensão psíquica devido à insuficiência de maturidade, dependência financeira, insegurança quanto ao seu desejo de ser mãe, falta do apoio dos familiares. ${ }^{3}$ Os riscos à saúde do bebê estão relacionados aos aspectos clínicos tendo em vista que bebês nascidos de mães jovens são propensos a apresentar baixo peso e a morrer de desnutrição e problemas infecciosos no primeiro ano de vida. ${ }^{4} \quad$ Assim, a preocupação com as adolescentes e sua gestação se deriva do fato de 0 baixo peso ser prevalente nos recém-nascidos, apesar de também envolver riscos psicológicos e sociais. ${ }^{5}$

Os riscos sociais que incluem os filhos de adolescentes relacionam-se às dificuldades socioeconômicas dos pais e à perpetuação do modelo da gestação na adolescência. As adolescentes que iniciam a vida sexual precocemente ou engravidam nesse período geralmente vêm de famílias cujas mães tiveram uma biografia semelhante, ou seja, também iniciaram a vida sexual precocemente ou engravidaram durante a adolescência. Neste sentido, os riscos à saúde da adolescente têm maior peso em relação às condições culturais e sociais em que a gestação ocorre do que propriamente pela idade. ${ }^{6}$

Grande parte dos estudos já produzida focaliza a gravidez na adolescência vista pelo prisma dos preconceitos. Estes estudos situados no plano biomédico gravitam no discurso de que a gravidez na adolescência é um problema de saúde; no plano patológico, apontam o risco, fortalecido pela ideia de que o parto em adolescentes é cirúrgico; no plano social, assinalam que adolescentes não têm condições socioeconômicas para manutenção do filho; e na concepção de gênero, afirmam que o parceiro adolescente é alguém que não se envolve no processo gestacional.

Todavia, a gestação pode ser encarada também como um desejo ou um projeto de vida de adolescentes e, portanto, envolve a participação de ambos os parceiros, pois é uma experiência a ser compartilhada a dois. ${ }^{7-8}$

Tendo em vista que o ciclo gravídico-puerperal pressupõe o envolvimento do casal, chama a atenção o fato de que a sociedade venha focalizando esse fenômeno como de responsabilidade exclusiva da adolescente, embora seja do conhecimento de todos que ela não engravida sozinha e que o relacionamento deve ser baseado no respeito entre os parceiros e em responsabilidades compartilhadas, voltadas à construção de parcerias igualitárias. ${ }^{9}$

0 ciclo gravídico-puerperal ainda se encontra obscuro porque tem sido estudado a partir dos conceitos prévios da ciência e dos fatos que não respondem ao questionamento: 0 que significa para o casal adolescente vivenciar a gestação?

Em busca de analisar compreensivamente os significados da gestação na adolescência na concepção do casal, este estudo tem como objeto os significados da vivência da gestação na adolescência para o casal. E como objetivo: analisar o movimento existencial do casal adolescente que vivencia uma gestação. Nesse sentido, pretende-se vislumbrar a compreensão desse processo a partir dos aspectos factuais, buscando, porém, um olhar atentivo ao caráter fenomenal.

A gravidez na adolescência aponta para a necessidade de adaptações e reestruturações, caracterizando-se como um período de transição. É marcado por profundas mudanças corporais, psíquicas e sociais e sinaliza transformações significativas para jovens de ambos os sexos, inserindo-os no mundo adulto. ${ }^{10}$

A gestação para os adolescentes pode significar uma rápida passagem da situação de filha/filho para a de mãe/pai, em uma transição do seu papel social de mulher/homem ainda em formação para o de adulto, podendo trazer à tona uma situação de crise e conflito ou de crescimento e amadurecimento.

Durante a gestação e após o nascimento surge 0 sentido da maternidade, transformando a adolescente em mãe, que necessita do apoio familiar e afetivo para assumir essa identidade, o que evidencia a importância do apoio do companheiro e de outros membros da família para que consiga transitar da adolescência para a função materna. ${ }^{11-12}$

A gravidez e o parto são eventos sociais que integram a vivência reprodutiva de um casal; assim, pode ser pensado como uma experiência singular no universo da adolescente e de seu parceiro, a qual congrega também suas famílias e a comunidade. 
Ao compreender que a adolescente não pode assumir sozinha as consequências de uma gravidez, deve-se considerar a presença do parceiro que concorre para o efetivo desenvolvimento da gravidez e reduz os efeitos desfavoráveis à saúde do bebê. ${ }^{13}$

A gestação, parto e puerpério podem se constituir uma vivência humana das mais significativas, com forte potencial positivo e enriquecedor para todos que dela participam. ${ }^{14}$

A gravidez na adolescência tem sido apontada como um importante fator precipitante da união não formal e coabitação entre os casais. ${ }^{15}$ Enfatiza-se, portanto, a necessidade de se enfocar a história pessoal, o contexto socioeconômico, assistencial e existencial, que se relaciona ao casal adolescente para se compreender sua vivência.

0 ciclo gravídico puerperal é um processo dinâmico, mutável, socializador, no qual é necessário considerar aqueles envolvidos nesse período/processo a fim de se conhecer os fatores aos quais se relaciona. ${ }^{3}$

Os papéis referentes à maternidade e paternidade, determinados pelo contexto sociocultural, representam faceta relevante na constituição da relação de casal, através dos modos específicos de lidar com as questões da procriação e dos cuidados com os filhos, que são definidos pelo enfoque de gênero. ${ }^{16}$

0 contexto social no qual o fenômeno maternidade/ paternidade adolescente se desenvolve e os principais desdobramentos na vida dos sujeitos, advindos do nascimento da criança, são questões fundamentais para analisar a experiência de parentalidade juvenil, o que possibilita visualizar a situação dos jovens nesse processo. ${ }^{16} \quad$ Ademais, 0 desenvolvimento de um relacionamento sadio, baseado no afeto e compreensão, pode minimizar comprometimentos e dificuldades advindos do período gestacional e estabelecer um bom vínculo familiar.

Compreende-se, então, que o processo parturitivo pode se construir durante a gestação, de acordo com a história de cada casal, a partir de sua intersubjetividade. Assim, 0 vivido do gestar estará influenciando o parir e as relações subsequentes do casal adolescente-com-o-concepto, nas quais está subentendido o nutrir.

\section{METODOLOGIA}

Este é um estudo qualitativo, de natureza descritiva, utilizando a abordagem fenomenológica à luz dos conceitos de Martin Heidegger. Este filósofo alemão buscava a compreensão do sentido da existência humana através da Fenomenologia Ontológica que visa às questões do ser. 0 ser é o conceito mais universal do Homem, que não se define, pois é evidente por si mesmo, não podendo ser explicado. ${ }^{17}$

No entanto, as questões referentes ao ser possuem obscuridades que necessitam ser desveladas. Nessa pesquisa o que está velado é a vivência dos adolescentes que engravidam, embora a perplexidade de "todos" questione se na adolescência existe a relação de casal. Essa opacidade da visão foi caracterizada pelo pensamento dominante que determina que, na adolescência, a gestação é, por uma questão de gênero, responsabilidade da adolescente.

Com esse entendimento, faz-se nítido a importância de se ter uma abordagem que perceba o ser como possibilidade e revele o que está velado pelos significados, Portanto este estudo, sustentado na perspectiva de que a visão de mundo do pesquisador oportuniza um olhar compreensivo ao fenômeno, fundamentou-se em uma proposta fenomenológica. ${ }^{18}$

Nesta investigação, o cenário foi selecionado em consonância com a proposta do estudo e em coerência com a abordagem metódica, sendo uma unidade de saúde que desenvolve atendimento humanizado e de qualidade no âmbito da assistência materno-infantil. 0 local para a realização desta pesquisa foi a Casa de Parto David Capistrano Filho, unidade da Secretaria Municipal de Saúde do Rio de Janeiro.

A realização das entrevistas deu-se no período de março a outubro de 2008 e foi precedida de autorização do Comitê de Ética em Pesquisa da Secretaria Municipal do Rio de Janeiro, mediante aprovação do protocolo de pesquisa 14/08.

Os depoentes do estudo foram nove casais adolescentes que vivenciaram a gravidez na faixa etária entre 15 e 19 anos. Como critério ainda para participar do estudo, deveriam se compreender como casal, com ou sem documento oficial de casamento religioso ou civil e, juntos, terem tido a vivência do ciclo grávido mesmo habitando em casas separadas.

Como técnica utilizou-se a entrevista fenomenológica que permite mostrar, descrever e compreender as vivências mediante uma relação interpessoal mediada pela empatia e pela redução de pressupostos. A questão orientadora "Como foi para vocês a vivência da gestação" permitiu a descrição do vivido do casal adolescente. Os depoimentos foram gravados em fita magnética e/ou através de dispositivo MP3 a partir da autorização dos adolescentes e seus responsáveis legais.

Atendendo às questões éticas de pesquisa, a autorização dos entrevistados se deu antes de cada entrevista, por meio da assinatura do termo de consentimento livre e esclarecido. A identidade dos entrevistados foi preservada e seu anonimato garantido através da utilização de um pseudônimo.

0 número de entrevistas não foi definido previamente, pois se pretendeu atender a captação de significados que apontassem para o desvelamento do fenômeno que se encontrava encoberto.

\section{RESULTADOS E DISCUSSÃO}

A compreensão vaga e mediana é o momento da análise que representa, na visão dos sujeitos pesquisados, a dimensão dos fatos por eles vivenciados. É o primeiro momento analítico do método heideggeriano, no qual, após a escuta repetida das falas e de sua transcrição, pode-se apreender significados. Após 
esta compreensão é possível constituir, mediante a análise hermenêutica, o movimento existencial em direção a um sentido presente e expresso pelos depoentes, mas que antes estava velado pelos significados, caracterizando sentido como aquilo em que se sustenta a compreensibilidade de algo. ${ }^{17}$

A leitura atentiva do conteúdo das entrevistas permitiu analisar cada fala e penetrar na realidade dos adolescentes, captando suas significações, diferenciando as estruturas acidentais ou ocasionais. As estruturas essenciais são aquelas que mais emergem nos discursos dos sujeitos a partir dos significados de suas vivências. Esse momento caracteriza-se como o início da análise compreensiva, ou primeiro momento metódico. 0 conjunto de significados denomina-se unidade de significação; por meio desta, construiu-se o fio condutor, lendo e relendo repetidas vezes as transcrições, na expectativa de desvelar algumas facetas do fenômeno gestar para o casal adolescente. ${ }^{17}$

Os casais adolescentes mostraram-se em sua cotidianidade mediana através das modalidades de acesso (questionamento) e interpretação fundamentada pela análise heideggeriana. Para tanto, foram apreendidas as estruturas significantes para os jovens em relação àquilo que estava obscuro e que eles conseguiram em si mesmos e por si mesmos significar.

\section{A vivência da gravidez para o casal adolescente significou:}

1. Passar pela dificuldade de contar para os pais, para a família, enfrentando sentimentos medo, susto, choque e conformação

Ela: Minha mãe entrou em pânico, porque minha mãe não esperava... minha mãe entrou em pânico. Mas o maior problema foi meu padrasto, porque ele não aceitava. Eu sempre fui uma filha para ele, me criou desde pequena, então fez aquele papel de pai de não aceitar, né? Queria me botar pra fora de casa, chorou ... Ele chorou muito, mas depois acabou aceitando e aquilo tudo. [...] E isso, ainda teve aquela maior pressão... porque eu fiqueigrávida com quatro meses de namoro. Ele: [...] ela falou com a minha mãe, ó...suspeita disso, disso, disso. Chorou comigo(a mãe), falou por que que eu fiz isso [...] Falamos com a minha mãe... [...] a minha mãe ligou pra mãe dela. (0 Cravo e a Rosa)

Ele: Na realidade, difícil foi só falar...Ela: É aquilo que eu já falei... Difícil mesmo foi só no começo, porque a gente descobriu e pra falar... (Giuseppe e Anita Garibaldi)

Ela: Quando foi chegando perto lá de casa, no portão, eu estava pensando no caminho todo como que eu ia falar pra ele, né? Aí, quando chegou lá no portão lá de casa, que a gente desce do carro... quando a gente chegou lá dentro... no portão lá de casa, aí eu peguei falei. Falei D. tô grávida. Ele tomou aquele susto... né? Ele: Aí, eu cheguei, conversei com a mãe dela, aí a mãe dela também deu aquela conformada, porque é aquilo, ela é filha única de mulher. Então, pra mãe dela, pro pai dela se conformar, é muito difícil. (Romeu e Julieta)

2. Ter que contar com a ajuda de todo mundo, com o apoio e a aceitação da família, que apesar de tudo ficou feliz.

Ele: [... mas aí, com a ajuda de todo mundo, todo mundo ajuda, todo mundo ajuda um pouquinho... Até hoje todo mundo ajuda... a gente vai ... tentando viver [...] Ela: [...] a mãe dele adorou, né... de cara [...] ela adorou [...] Acho que desde o comecinho que ele falou que eu estava grávida, ela me paparicou, né? O tempo todo. Até hoje. Tanto a ele, quanto eu também. Como nora dela, ela foi uma... ela é uma sogra e mãe, né? Até hoje. Porque, paparica a beça.... [...] Então, acho que não foi difícil porque a gente teve muito apoio, dos dois lados. (Giuseppe e Anita Garibaldi)

Ela: Mas sempre tem alguém aqui que ajuda a gente. Ensina, assim... Ele: [...] Minha mãe, minha avó, meu pai, padrasto. Toda minha família. (Lua e Sol)

Ela: Também porque todo mundo ficou feliz, todo mundo aceitou. Não... não falou nada, minha mãe. Todo mundo... E foi bom... A gravidez inteira sendo paparicada...Ele: E aí, também, pelo menos a família dela... gosta de mim [...] (Tarzan e Jane)

3. Uma experiência nova, meio estranha, meio assustadora, que dá nervoso/deixa nervosa e no início não é bem aceita ... mas que pode ser boa conforme o tempo passa

Ela: Ah, no começo foi meio estranho. Porque... a gravidez na adolescência é uma coisa meio estranha. Ele: Quando a gente descobriu, aí já era outubro, final de novembro, né? Passados trinta dias, já... mês de novembro. Fazer agora, fazer o quê, né? Aparentemente, a ficha dela ainda não tinha caído. Tanto pra mim, quanto pra ela. Estava normal, não estava sentindo nada.(...) Quando ela começou a sentir os primeiros sintomas da gravidez, ela teve um choque interno.

10 Cravo e a Rosa) 
Ela: Aí fiquei passando mal. E eu não sabia que tava grávida. Isso eu fiquei uns dois meses passando bem mal, mesmo. Fiz exames e tudo e não constava nada. Até que eu fui fazer a ultrassonografia, que o médico tinha pedido pra ver se era alguma coisa. Deu que estava grávida. Aí, quando eu saí da sala, eu fiquei bem nervosa, eu... não... aceitei muito não no começo, eu não queria não. Ele: Aí, eu passei pra ela que aquilo ali não era um problema, era mais ou menos uma responsabilidade a mais que a gente ia ter que ter, entendeu?(Romeu e Julieta)

Ele: Pra ela e pra mim foi bom. Ela: Experiência nova, diferente, meio assustadora, mas foi bom. Minha gravidez foi ótima, foi uma experiência nova que eu amei, amei, amei [...] (Charles e Diana)

0 casal adolescente que vivenciou a gestação expressou seu vivido ao revelar que no começo passou pela dificuldade de ter que contar para os pais, para a família... enfrentando sentimentos de medo, susto, choque e conformação, pois ao descobrir a gravidez não sabiam como falar. Sendo assim, foi difícil contar, pois a família não esperava, e em alguns momentos chegou a entrar em pânico e se assustar, por não aceitar o fato. Ao falar da gravidez, familiares entraram em contato uns com os outros, e a emoção foi exteriorizada através do choro. Alguns pais brigaram e ficaram chateados, como era esperado pelos jovens, que compreendem inclusive quando o fato se dá com filhas únicas. Assim, os casais verbalizaram sua dificuldade para falar e revelar a notícia da gravidez, demonstrando-se temerosos pela reação dos pais, dos responsáveis e até do próprio parceiro. Para assumir a gravidez, a decisão teve que acontecer de forma conjunta, como uma responsabilidade do casal. Além disso, tiveram que contar com a ajuda, o apoio e a aceitação da família, que, apesar da surpresa, passou a aceitar, ao entender que é uma coisa normal que poderia acontecer.

0 casal adolescente ao falar sobre o vivido de gestar-ofilho revela sua percepção de que a gravidez na adolescência é estranha e de que, quando aparecem os primeiros sintomas, causa choque, medo, é difícil aceitar.

Para o casal, o gestar, ver a barriga crescendo e viver as mudanças cotidianas e corporais como 0 aparecimento de estrias, o aumento de peso, bem como a movimentação do bebê, pode caracterizar o estranhamento. As transformações podem levar os adolescentes à dualidade de sentimentos, entre querer e não querer a gestação.

Por viver uma experiência nova e porque ainda é adolescente, o casal teme por não poder mais sair, por pensar que não vai mais poder estudar, que a gravidez pode atrapalhar seus planos e seu futuro. Mas, com o passar do tempo e com o evoluir da gestação, vai se acostumando e gostando; e passa a ser uma experiência boa que leva ao aprendizado.

A análise heideggeriana aponta que os casais adolescentes, ao se descobrirem "grávidos", se sentem sob o domínio da ameaça e do temor em sua cotidianidade mediana. 0 temor é definido pelo que se teme, que no caso dos jovens é revelar a gravidez.

0 temor é angústia imprópria e possui o caráter de ameaça, pois o ser-casal não esperava a possibilidade de ter que contar sobre a gravidez. Angústia imprópria é negar a possibilidade, assim o casal adolescente aceitou a facticidade da gestação porque teve relações sexuais, mas negou a possibilidade de ter que revelar a notícia da gravidez.

0 ser-casal-adolescente apresentou-se temeroso por ter que contar sobre a gravidez e mostrar ao mundo público que já não era mais como todos adolescentes, ou como se esperava que fosse. Assim, esteve dominado pelo modo da disposição fundamental do temor. 0 contar é uma compreensão do significado de ser-casal-adolescente que se tornou ser-casalgrávido, tendo que afirmar para o mundo público que engravidou.

No modo de ser temendo, coexistem três perspectivas: o que se teme, o temer e pelo que se teme. 0 que se teme é um ente que vem ao encontro no mundo, possuindo o modo do ser simplesmente dado e é temível por possuir o caráter de ameaça. A ameaça possui o modo conjuntural de dano, que se aproxima e irradia. 0 aproximar-se ocorre dentro da proximidade e continuamente propicia a temerosidade. 0 que pode ser danoso tem o caráter de ameaça por estar chegando e, ao se tornar próximo, amedronta. 0 temor descobre a ameaça que se aproxima e que em sua temeridade esclarece para si o temível. ${ }^{17}$

Ao temer, a ameaça é liberada, se torna real e, ameaçando, traz o caráter de temível; o temível é como os pais irão reagir. 0 ser-casal-adolescente-grávido, ao temer por ter que contar, liberou a ameaça que se deu em função de imaginar a possibilidade de reação dos pais, que poderia ser de não oferecer apoio social, emocional, financeiro, e até de separá-lo.

A análise compreensiva heideggeriana aponta que 0 ser-casal-adolescente, ao se descobrir "grávido", se sentiu sob o domínio da ameaça e do temorem sua cotidianidade mediana de ser-com. A dificuldade do ser-casal-adolescente como sendocom que teme-junto, manifestou seu temor de perder o "com", tornar-se ser-só, uma modalidade deficiente do ser-com.

0 ser-aí, em sua cotidianidade, não está simplesmente no mundo, é fascinado e absorvido pelo mundo e a ele está ligado, é ser-no-mundo. A expressão ser-no-mundo comporta a ideia de mundanidade do mundo, e o ser-no-mundo preocupase em realizar ações e concretizar um fazer, por isso ocupa-se e também cuida de outros seres-aíe entes simplesmente dados (coisas) com os quais compartilha o mundo. ${ }^{17}$

0 mundo do ser-aídesvela outros entes encontrados também no mundo. Assim, o ser-aí-no-mundo não é um eu 


\section{Gestação na adolescência com enfoque no casal}

isolado de outros seres, é um ser vivendo junto a outros no mundo circundante, o mundo familiar, portanto, é ser-com. Sercom é um constitutivo fundamental do ser-aí, tem origem no latim (Cum) e no grego (syn), significando junto a algo e alguém, evidencia, portanto, o relacionar-se, atuar, sentir, pensar, uma característica do humano em suas relações. ${ }^{17}$

0 ser-com é uma característica existencial do ser-nomundo, não é apenas o estar-junto, é relacionar-se, envolverse, correlacionar, conviver, compreender e compartilhar. 0 ser do humano partilha com os outros o seu espaço, mantém interação com os demais entes, é tão ser-com que não há possibilidade de viver só. Sozinho é incompleto, e quando está só percebe a co-pre-sença dos outros pela sua ausência. ${ }^{17}$

Assim, o Dasein, pre-sença, ser-no-mundo, é fundamentalmente ser-com-o-outro, percebendo o outro em suas características e necessidades, relacionando-se com o outro sem tomar o seu lugar, sem viver o vivido do outro, sem interferir em sua experiência pessoal. ${ }^{19}$

Ser-no-mundo é viver e habitar um mundo e sendono-mundo, co-habitar, é ser-com-os-outros; desse modo, as vivências são con-vivências, a pre-sença é co-pre-sença, o mundo é com-partilhado. ${ }^{17}$

0 modo do cotidiano de ser-próprio é fundado pelo ser-com e pela co-pre-sença, estruturas da pre-sença igualmente originárias. A pre-sença (ser-aí) encontra a si mesma e a co-pre-sença no mundo circundante, em que se ocupa e se pre-ocupa. ${ }^{17}$

A pre-sença, como ser-com, é o fundante da preocupação, na convivência cotidiana e mediana de todos. Preocupação é a maneira de se envolver, cuidar e se responsabilizar pelo outro. E possui, em seu modo positivo, duas possibilidades de cuidado: o cuidado dominador, que retira do outro a possibilidade de cuidar-se e o cuidado libertador, que respeita a existência do outro e o ajuda a tornar-se livre para cuidar de si. A convivência cotidiana se dá por esses dois modos de preocupação e por suas formas mistas. ${ }^{17}$

Como ser-aí, pre-sença, o ser-casal-adolescente vive em um mundo de fatos e de fenômenos, em que o existir se propaga em uma pluralidade de relacionamentos, situações e vivências. 0 ser-casal é ser-com, pois relaciona-se entre si e, através do fenômeno da gestação, relaciona-se com o bebê. Vivendo no mundo, o ser-casal é ser-no-mundo, por viver em um mundo de con-vivências e por sua característica mais própria de ser, o ser-aí-casal-adolescente vive em conjunção a outros, compartilha, vive seu modo de ser-adolescente com os amigos, colegas, grupos e mais significativamente com os pais, a quem se remete quando necessita de apoio e orientação. Desse modo, os pais são para os filhos as fontes de cuidado, de suporte financeiro, emocional, social, são, enfim, a base para a sobrevivência do filho.

Os pais do ser-casal são com ele, do mesmo modo que ele é com-seu-filho desde a concepção, que, neste estudo, vem à tona com o resultado do exame de gravidez e com a descoberta/notícia de seu resultado. Sendo pais do casal adolescente, mesmo mediante o impacto da surpresa da gestação, são ser-com como todo ser-ek-sistente-nomundo, pois sendo-no-mundo não existe a possibilidade de ser sozinho, desse modo apoiam, ajudam, cuidam e se preocupam com o ser-casal para que ele não se sinta só. Quando ocorre a gravidez, o modo de ser no mundo dos pais do ser-casal-adolescente em seu ser-com-o-outro se mostra no modo da preocupação. Esse modo de ser-como-ser-casal revela que os pais - pre-sença familiar - tanto se ocupam quanto se preocupam em decorrência da gravidez.

Ao conviver com o ser-casal-adolescente, os pais compreenderam suas demandas de ajuda, orientação e apoio em todo o período gravídico-puerperal e, conhecendo o ser-casal, perceberam seu envolvimento com a gestação, sendo co-pre-sença atenta às suas necessidades.

Assim, os pais do ser-casal-adolescente são-comele na experiência de gestar, em uma pre-sença significante, e marcam o seu cuidado libertador ao proporcionar apoio/ajuda/suporte, dando-lhes espaço para ser e crescer como necessitam.

Ter apoio em seus momentos de apreensão foi essencial para que o casal tivesse segurança, se sentisse protegido e tivesse tranquilidade para se lançar como "projeto". Portanto, pode se mostrar como realmente é na modalidade de ser-casal em sua dimensão existencial acontecendo no tempo, através da possibilidade fenomenal de gestar-o-filho como ser-no-mundo cotidiano.

0 casal adolescente, ao entender a gravidez como possibilidade e ao se sentir apoiado, faz um movimento existencial em direção à compreensão e aceitação, indo da instância ôntica (factual) para a instância ontológica (fenomenal), mostrando-se como ser-de-possibilidades.

0 ser-casal-adolescente anuncia que possui a potencialidade de ser-mais, de viver de acordo com suas necessidades, recriar o seu cotidiano e dar impulso a seus planos, em seu contexto vivencial/existencial.

A característica do ser-aí como ser-no-mundo tem o caráter do projetar compreensivo. Por ser o ser-no-mundo um existencial, o humano é um produto sempre inacabado, ou seja, enquanto existe, possui a capacidade de se tornar; pode ser algo que ainda está por ser. ${ }^{17}$ No vivido de gestar, o ser-casal conta com a co-presença dos pais e reconhece que sendo-com-eles pode ser-com-o-filho.

A temporalidade mostra que o casal passa a viver 0 presente pensando o passado e projetando o futuro. Este movimento existencial mostra que o ser-casal-adolescente é um ser-de-possibilidades, no qual se projeta. Nesse sentido, no vivido da gestação, mostrou-se como ser-depossibilidades em um modo de existir projetivo. 


\section{CONSIDERAÇÕES FINAIS}

A experiência da gestação para o casal de adolescentes ainda está impregnada por muitos preconceitos; no entanto, seus significados e vivências podem contribuir não só para a aproximação dos jovens de suas famílias como também para seu amadurecimento, definindo assim mais uma área de cuidado para o profissional de enfermagem e para os membros da equipe de saúde em um enfoque interdisciplinar.

Desse modo, os profissionais têm a possibilidade de exercer o cuidado com solicitude ao casal adolescente, configurando a necessidade real de se criar oportunidades no cotidiano nas quais estes possam pensar, planejar e avaliar suas ações e exercer efetivamente seus direitos reprodutivos. E a equipe de saúde pode auxiliar: no enfrentamento de momentos conflituosos; na compreensão de sua ambiguidade de sentimentos e na apreensão de comportamentos geradores de práticas saudáveis em relação a gravidez e ao desenvolvimento do concepto. Portanto, faz-se necessário disponibilizar espaços para a escuta dos jovens, possibilitando dar visibilidade a suas necessidades durante o processo reprodutivo.

Compreender o casal adolescente, em seu vivido de gestar, ou seja, no cotidiano de ser-casal, permite construir outras possibilidades de cuidado sustentadas na instância ontológica, velada no cotidiano assistencial que é operacionalizado pelo protocolo de risco gestacional.

Portanto, a gravidez na adolescência pode ser vista para além do rótulo de problema, pois sua ocorrência traduz-se como possibilidade à orientação das ações profissionais em torno da questão. Discutir essa temática e buscar desconstruir essas verdades, mitos e tabus não significa desvalorizar ou invalidar os componentes de estudos anteriores, bem como não significa fomentar a gravidez entre os jovens, e sim poder vislumbrar novas possibilidades e respeitar seus direitos sexuais e reprodutivos. Seguindo nesse pensar, os serviços de pré e pós-natal podem dispor de espaço e linguagem para interlocução com os adolescentes grávidos, em um investimento que venha a preservar sua saúde e compreendê-los como seres de possibilidades. Ao refletirmos sobre a gravidez na adolescência na perspectiva do casal, sem a imposição de juízos de valores, dando-lhes voz, poderemos compreender seus sentimentos, percepções e comportamentos e, assim, tornar visível o fenômeno situado naqueles que o vivenciaram trazendo repercussões, do ponto de vista da promoção de saúde.

Transcendendo a visão normativa de que adolescentes não devem engravidar porque, entre outras perspectivas, precisam completar seus estudos, esta pesquisa buscou se despir de juízos de valor e de preconceitos e compreender singularidades existentes ampliando o olhar ao outro, o casal adolescente que necessita de uma assistência menos calcada em modelos e protocolos e mais referenciada por ações de apoio, solicitude e cuidado, que, sendo libertador, o leve a ser-mais.

\section{REFERÊNCIAS}

1. Barreto ACM, Almeida IS, Ribeiro IB, Tavares KFA. Paternidade na adolescência: tendências da produção científica. Adolescência \& Saúde. 2010; 7(2): 54-59.

2. Pantoja ALN. "Ser alguém na vida": uma análise sócio-antropológica da gravidez/maternidade na adolescência, em Belém do Pará. Cad Saude Publica. 2003; 19 (supl 2): S335-S43.

3. Silva JLP. Gravidez na adolescência: uma visão multidisciplinar. In: Saito MI, Silva LEV, coordenadores. Adolescência: prevenção e risco. São Paulo: Atheneu; 2001: 299-305.

4. Cannon LCR, Serra ASL, Pereira AA, Santos JD, Magalhães ML, Mota MSFT. et al. Saúde e desenvolvimento da juventude brasileira. Construindo uma agenda nacional. Brasília(DF): Ministério da Saúde/ Secretaria de Políticas de Saúde; 1999.

5. Gontijo DT, Medeiros M. Gravidez / maternidade e adolescentes em situação de risco social e pessoal: algumas considerações. Rev Eletr Enferm. 2004; 6(3): 25-37. [citado 2010 nov 10].Disponível em: www.fen.ufg.br.

6. Gama SGN, Szwarcwald CL, Leal MC. Experiência de gravidez na adolescência, fatores associados e resultados perinatais entre puérperas de baixa renda. Cad Saude Publica. 2002; 18(1): 153-61.

7. Maldonado MT, Dickstein J. Nós estamos grávidos. Rio de Janeiro: Integrare; 2010. 240 p.

8. Ministério da Saúde (BR). Secretaria de Atenção à Saúde. Departamento de Ações Programáticas Estratégicas. Direitos sexuais, direitos reprodutivos e métodos

Brasília(DF); 2006. 52 p.

9. Abeche AM, Maurmann CB, Baptista AL, Capp E. Aspectos sócioeconômicos do parceiro da gestante adolescente. Rev HCPA. 2007; 27(1): 12-7.

10. Zagonel IPS, Martins M, Pereira KF, Athayde J. 0 cuidado humano diante da transição ao papel materno: vivências no puerpério. Rev Eletr Enferm[on-line] 2003 [citado 2010 nov 10] 5(2): 24-32. Disponível em: http://www.revistas.ufg.br/index.php/fen/issue/view/ 77.

11. Hoga LAK, Borges ALV, Reberte LM. Razões e reflexos da gravidez na adolescência: narrativas dos membros da família. Esc Anna Nery. $2010 \mathrm{jan} / \mathrm{mar} ; 14$ (1): 151-57.

12. Costa MCO, Lima IC, Martins Júnior DF, Santos CAST, Araújo FPO, Assis D. Gravidez na adolescência e co-responsabilidade paterna: trajetória sociodemográfica e atitudes com a gestação e a criança. Cienc Saude Colet. [periódico on-line] 2005 set [citado 2010 nov 11] 10(3): 719-27.Disponível em: http://www.scielo.br/scielo.php?script=sci_arttext\&pid=S141381232005000300028 \&lng =en.doi:10.1590/S141381232005000300028 . 
13. Ministério da Saúde(BR). Parto, aborto e puerpério: assistência humanizada à mulher. Brasília(DF); 2001.

14. Motta MGC, Ribeiro NRR, Pedro ENR, Coelho DF. Vivências da mãe adolescente e sua família. Acta Sci., HealthSsci. 2004; 26(1): 249-56.

15. Abeche AM. A gestante adolescente e seu parceiro: características do relacionamento do casal e aceitação da gravidez. Rev Bras Ginecol Obstetr. 2003; 25 (7): 535-35.

16. Dias AB, Aquino EML. Teenage motherhood and fatherhood: observations in three cities of Brazil. Cad Saude Publica [on-line] 2006 [citado 2006 out 18] 22(7):1447-458. Disponível em: http:// www.scielosp.org/scielo.php

17. Heidegger M. Ser e tempo. p 1. 12a ed. Petrópolis: Vozes, 2002. $325 p$.

18. Almeida IS, Crivaro ET, Salimena AM, Souza, IEO. 0 caminhar da enfermagem em fenomenologia: revisitando a produção acadêmica. Rev Eletr Enferm. [on-line] 2009 [citado 2010 nov 10] 11(3): 69599.Disponível em: http://www.fen.ufg.br/revista/v11/n3/ v11n3a30.htm

\section{NOTA}

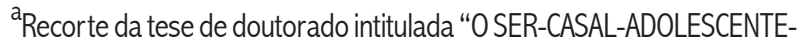
NO-VIVIDO-DE-GESTAR-PARIR-E-NUTRIR: uma abordagem existencial como possibilidade para a Enfermagem", desenvolvida no Programa de PósGraduação e Pesquisa, Núcleo de Pesquisa de Enfermagem em Saúde da Criança (NUPESC) da Escola de Enfermagem Anna Nery, da Universidade Federal do Rio de Janeiro (UFRJ). 